\title{
The Correlation Between Spiritual Health With the Coping Ability of the Clients Towards the Pain in the Labour Process Within the Work Area of Ibrahim Adjie's Community Center in Bandung 2019
}

\author{
$1^{\text {st }}$ Maya Sukmayati \\ Midwifery Study Program \\ Sekolah Tinggi Ilmu Kesehatan' Aisyiyah Bandung \\ Indonesia \\ msukmayati@yahoo.com
}

\begin{abstract}
This study is aimed to find out a correlation between spiritual health with the ability of pain coping strategy among women in intrapartum. According to the theory, spirituality is known as one of the health dimensions and has a connection with the ability of pain coping strategy. There were 30 women in intrapartum filled the questionnaires of the Spiritual Well-Being Scale and The Ability Of Pain Strategy Scale to assess spiritual health and the ability of pain coping strategy of intrapartum women. The data were analysed by Spearman's rank and showed Pvalue 0.05 had no significant correlation between Spiritual Health with the ability of Pain Coping Strategy among Intrapartum Women.
\end{abstract}

Keywords - health, pain strategy, spiritual, intrapartum

\section{INTRODUCTION}

The fulfilment of excellent health services and quality of life will continue to grow, along with changing times and increasing public awareness. What community needs from health services nowadays is not only to prevent and cure, so people are not physically ill, but also to support holistic health. The caregiver provides holistic health, including physical, mental, spiritual, and social needs, to the community as its purpose has long emphasised by The constitution of the Health of the Indonesian Republic [1], [2]. Unfortunately, the quality of fulfilling holistic health care in our country is still very far from the purpose of the law. Even until now, health and midwifery care received by the community still oriented towards physical assistance, a little mental and social welfare assistance, but does not yet support spiritual well-being [2], [3,04] The other case, many health caregivers who feel uncomfortable with the element of spiritual care and unconfident about how to assess and give spiritual care in the scope of their professional role has made the hole in holistic care [4]
Experts have added spirituality as one of health's dimension after much criticism directed against the definition of health by WHO 1948, which its thought too general and ideal while being healthy is the right of every human. Besides, the existence of continuous research and studies related to community needs for better health quality fulfilment requires not only physically, mentally, but also socially and spiritually [5], [6].

There were several studies have found a significant relationship between spiritual health and physical wellbeing [7]. Health caregivers, including midwives, should understand the need for spiritual health that must give to clients. It needs material related to spiritual care that health caregiver should learn and be skilled before, though [8]

\section{METHOD AND DESIGN}

This study purposes addressing the relationship of the spiritual health of the intrapartum clients with their coping ability towards the pain in the labour process. This part of the research report contains the study method and design, sampling, data collection, instruments, procedure, and protection of human subjects.

\section{A. Method}

The method of the research is the holistic steps which the researcher should begin. This research method is using a quantitative study to determine a relationship exists between two or more variables within a sample or population [9]. This study is aimed to analysing the correlation between spiritual health with the coping ability of the clients toward the pain in the labour process within the work area of Ibrahim Adjie's Community Center in Bandung 2019. 


\section{B. Sampling}

To ensure that research subjects can be represented by the samples that meet the requirements, the study uses the inclusion and exclusion criteria. The inclusion criteria are the client at the first stage of normal labour, Muslim, and willing to be a respondent. Exclusion criteria: a client with gynecologic, obstetric complication, and refer to the hospital.

The Consecutive technique is applying in the study to avoid the bias by recruit the number of respondents which is meeting the inclusion criteria within a month[10].

C. Instruments

The study utilises a survey technique for collecting the number of information from respondents such as biodata, spiritual health and pain management condition through the questionnaire.

Pearson Product Moment Research was used to test the validity of the instrument and Alpha Cronbach for reliability testing before variables were measured.

In this study, the variables involved are:

1) The dependent variable is in the form of a client's ability to pain management strategy during labour. Information was measured through the adaptation of the Coping Strategies Questionnaire Scale in an Arabic LBP and Pain Coping Inventory questionnaire scale [11]-[13].

2) The independent variable in the form of the client's spiritual health condition with the instrument is an adaptation of the Functional Assessment of Chronic Illness Therapy-Spiritual well-being scale and the Islamic Spiritual Health Scale (ISHS) [14], [15].

\section{PROCEDURE}

The leading researcher, midwives at the study site, and surveyor were taking discuss for three times before collecting data, regarding the implementation of study procedures. The client's medical record was reviewed to selected participants. The midwives were examined potential participants to find out the meeting of criteria. Thirty intrapartum clients were informed, under responsible for the protection of human subjects before accepted and signed the informed consent then fill the questionnaires during the first stage of the labour process.

\section{RESULTS AND DISCUSSION}

\section{A. Results}

The results of the validity test with Pearson ProductMoment on the independent variables showed that there were three invalid questions, namely numbers 1,5 and 8 with validity levels moderate to very high $(0.50-0.90)$. The dependent variable test results showed 9 numbers namely items $5,10,12,13,16,17,18,19,20$ issued, the rest are used for instruments with the validity moderate to high (0.40 - 0.80).

The reliability test by Cronbach's Alpha of Pain Management Strategy as the dependent variable showed the result as 0.874 (good) and 0.964 (excellent) for the independent variable (spiritual health condition).

\section{B. Univariate Analysis}

\section{Characteristics table of respondents}

Among the 30 respondents, most of the participants graduated from Senior High School (14 persons), and $21(70 \%)$ participants used to be housewives, $11(36.7 \%)$ participants were pregnant for the first time (primigravida). Besides all the above, most the age of the participants are between 20-29 years old.

TABLE I. CHARACTERISTICS TABLE OF RESPONDENTS

\begin{tabular}{|c|c|c|c|c|c|c|c|c|c|c|c|c|c|c|c|c|c|c|c|c|c|c|c|c|c|c|c|}
\hline & \multicolumn{8}{|c|}{ Occupation } & \multicolumn{8}{|c|}{ Gravida } & \multicolumn{8}{|c|}{ Age } & \multicolumn{2}{|c|}{ Total } \\
\hline & & $\begin{array}{l}\mathrm{H} \\
\mathrm{W}\end{array}$ & $\%$ & $\begin{array}{l}\mathrm{P} \\
\mathrm{E}\end{array}$ & $\%$ & $\mathrm{E}$ & $\%$ & Std & $\%$ & 1 & $\%$ & $2-3$ & $\%$ & 4 & $\%$ & $>4$ & $\%$ & \begin{tabular}{l|l|}
$<20$ \\
\end{tabular} & $\%$ & $\begin{array}{l}20- \\
29 \\
\end{array}$ & $\%$ & \begin{tabular}{|c|}
$30-$ \\
39 \\
\end{tabular} & $\%$ & $>39$ & $\%$ & & $\%$ \\
\hline \multirow{5}{*}{ Edu } & $\mathrm{E}$ & 4 & 13.3 & 0 & 0 & 0 & 0 & 0 & 0 & 1 & 3.3 & 1 & 3.3 & 0 & 0 & 2 & 6.7 & 0 & 0 & 2 & 6.7 & 0 & 0 & 2 & 6.7 & 4 & 13.33 \\
\hline & J H.S & 5 & 16.7 & 0 & 0 & 1 & 0 & 0 & 0 & 1 & 3.3 & 2 & 6.7 & 3 & 10 & 0 & 0 & 1 & 3.3 & 3 & 10 & 2 & 6.7 & 0 & 0 & 6 & 20 \\
\hline & S H.S & 9 & 30.0 & 1 & 3.3 & 2 & 6.7 & 2 & 0 & 6 & 20 & 2 & 6.7 & 1 & 3.3 & 5 & 16.7 & 2 & 3.3 & 7 & 23.3 & 2 & 6.7 & 3 & 10 & 14 & 46.67 \\
\hline & Dipl & 3 & 14.3 & 0 & 0 & 1 & 3.3 & 0 & 0 & 3 & 10 & 0 & 0 & 1 & 3.3 & 0 & 0 & 0 & 0 & 3 & 10 & 1 & 3.3 & 0 & 0 & 4 & 10 \\
\hline & U & 0 & 0 & 0 & 0 & 2 & 6.7 & 0 & 0 & 0 & 0 & 2 & 6.7 & 0 & 0 & 0 & 0 & 0 & 6.7 & 1 & 3.3 & 1 & 3.3 & 0 & 0 & 2 & 0 \\
\hline & & 21 & 70 & 1 & 3.3 & 6 & 20 & 2 & 6.7 & 11 & 36.7 & 7 & 23.3 & 5 & 16.7 & 7 & 23.3 & 3 & 10 & 16 & 53 & 6 & 20 & 5 & 16.7 & 30 & 100 \\
\hline
\end{tabular}

\section{Independent Variable}

Spiritual health condition as an independent variable in this study is measured by 23 questions adapted from Functional Assessment of Chronic Illness TherapySpiritual well-being scale (questions number 1 to 7) and the Islamic Spiritual Health Scale (ISHS) (questions numbers 8 to 23 ).

The minimum, maximum, mean, range and standard deviation values were obtained, and then the criteria for the spiritual health condition of the respondents was categorised by the formula:
- $\quad$ Low Spiritual Condition $=X<100.7-9.6$

- Moderate Spiritual Condition = $100.7-1.19 .6 \leq \mathrm{X}$ $<100.7+1$ SD

- $\quad$ High Spiritual Condition $=100.7+1.19 .6 \leq \mathrm{X}$

Univariate analysis results showed that 14 respondents included in the low category, eight respondents included in the medium category, and eight respondents included in the high category.

Table II and Figure 1 of Independent Variable Frequency Distribution (Health Spiritual Conditions) 
TABLE II. DISTRIBUTION OF THE FREQUENCY

\begin{tabular}{|c|c|c|c|c|c|c|c|}
\hline Category & F & $\%$ & Mean & SD & Range & Min & Max \\
\hline Low & 14 & 46,7 & & & & & \\
\hline Moderate & 8 & 26,7 & 100,7 & 9,6 & 28 & 87,00 & 115,00 \\
\hline High & 8 & 26,7 & & & & & \\
\hline Total & 30 & 100,0 & & & & & \\
\hline
\end{tabular}

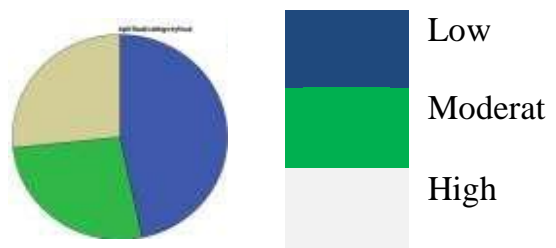

Fig. 1. Frequency Distribution Of The Spiritual Condition

\section{Independent Variable}

The ability of pain management is a dependent variable with 11 questions adapted from the Management Strategy Questionnaire Scale on the LBP Arabic scale and the Pain Management Inventory questionnaire scale. Once categorised, the results of the univariate analysis on the dependent variable are as follows: five respondents fall into the low category, 18 respondents fall into the medium category, and seven respondents fall into the high category.

Tables III and Figure 2 of Dependent Variable Frequency Distribution (The Ability Of Pain Strategy)

TABEL III. DISTRIBUTION OF THE FREQUENCY

\begin{tabular}{|c|c|c|c|c|c|c|}
\hline Category & F & $\%$ & Min & Max & Mean & SD \\
\hline Low & 5 & 16,7 & & & & \\
\hline Moderate & 18 & 60,0 & 27 & 52 & 37,2 & 6,8 \\
\hline High & 7 & 23,3 & & & & \\
\hline Total & 30 & 100,0 & & & & \\
\hline
\end{tabular}
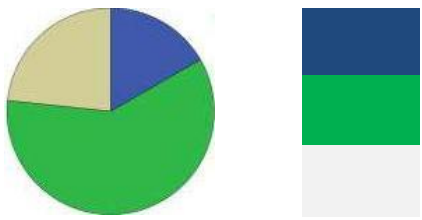

Low

Moderat

High

Fig. 2. Dependent Variable Diagram

Bivariate Analysis of the Relationship Between Independent Variables (Spiritual Conditions) With Dependent Variables (Client's Ability to Deal With Pain)

The results of statistical tests to see the correlation two variables in this study were conducted with Spearman's Rank because both scales of the dependent and independent variables are the ordinal type with the abnormal distribution. The analysis results obtained from the test differences between variables is 0.352 , which is expected to be insignificant because the sig (2-tailed) value is more than 0.05 .

TABEL IV. SPEARMAN'S RANK ANALYSES

\begin{tabular}{|c|c|c|c|}
\hline & Variable & & Value \\
\hline 1 & The ability of pain strategy & correlation coefficient & 0.176 \\
\hline 2. & Spiritual health condition & Sig. (2-tailed) & 0.352 \\
\hline & & $\mathrm{N}$ & 30 \\
\hline
\end{tabular}

\section{DISCUSSION}

According to this study, majority of the respondent's educations are Senior High School (30\%), housewives (70\%), pregnant for the first time or primigravidas
(36.7\%) and the age between 20-29 years old (53.3\%). Education's background of the participants is not too low to understand the birthing process but still is not enough to access some particular issue[16]. There are many 
determinants of knowledge, especially to access specific knowledge such as pain management in labour. The lack of experience among primigravidas about the birthing process also affects the ability of clients to cope with the pain. The age take part in the maturity of the spiritual condition[17].

Koenig found that religiosity and spirituality help protect the body from being negative and have a relationship with positive physical, psychological and mental health[18]. While for mothers, the process of giving birth is more of a time for god, using religious rituals and beliefs as a robust coping relationship. Also, giving birth is an experience of spiritual transformation[19]. Spirituality does not work with the intensity of the pain, but it could increase the ability to tolerate the pain[20]. So, the ability to manage the pain requires knowledge, techniques and practice to be trained. In this study, the ability of coping strategies for labour pain is not significantly related to a person's spirit because the respondent did not take any lesson about managing pain before. The characteristic of respondents may also contribute some effect to the ability of pain management.

\section{CONCLUSION}

This study showed no significan correlation between Spiritual Health With The Coping Ability Of The Clients Toward The Pain In The Labour Process, but it does not mean spiritual health does not work in labour process. It need education and training about spirituality and coping management during pregnancy, before clients enter to the birthing process.

\section{REFERENCES}

[1] DPR RI dan Presiden RI, "UU Kesehatan No 36." Kementerian Kesehatan RI, 2009.

[2] Menteri Kesehatan RI, "Standar Kompetensi Bidan.” Kemenkes RI, 2007.

[3] Presiden RI, "UU no 04 tahun 2019 Tentang Kebidanan." DPR, 2019.

[4] C. Drury dan J. Hunter, "The Hole in Holistic Patient Care," Open J. Nurs., vol. 06, no. 09, 2016. available: https://www.scirp.org/html/12-1440693_70974.htm.

[5] D. P. Friedman, C. C. Stine, dan S. Whalen, "Health and Wellness," dalam Lifetime Health, USA: Holt, Rinehart, Winston, 2004, 11-13.

[6] J. Keogh Rash, "Philosophical Bases For Health Education," in Philosophical Foundations Of Health, USA: Jossey-Bass A Wiley Imprint, 2010.

[7] A. Haynes, J. Hilbers, J. Kivikko, dan D. Ratnavuyha, Spirituality and Religion in Health Care Practice: a personcentred resource for staff at the Prince of Wales Hospital. Sydney: SESIAHS, 2007.

[8] L.-F. Wu, H.-C. Tseng, dan Y.-C. Liao, "Nurse education and willingness to provide spiritual care," Nurse Educ. Today, vol. 38. 36-41, 2016

[9] O. D. Apuke, "Quantitative research methode: A Synopsis approach," Arab. J Bug Manag Rev., vol. 6, no. 10. 39-47, 2017.

[10] B. Thewes $d k k$., "One way or another: The opportunities and pitfalls of self-referral and consecutive sampling as recruitment strategies for psycho-oncology intervention trials," PsycoOncol., vol. 27. 2056-2059, 2018, DOI: 10.1002/pon.4780.

[11] M. Heutink $d k k$., "Which Pain Coping Strategies and Cognitions Are Associated with Outcomes of a Cognitive Behavioral Intervention for Neuropathic Pain after Spinal Cord Injury?," Top. Spinal Cord Inj. Rehabil., vol. 19, no. 4. 330-340, 2013, DOI: $10.1310 /$ sci1904-330.
[12] F. Kraaimaat dan A. W M Evers, "Pain coping strategies in chronic pain patients: psychometric characteristics of the Pain Coping Inventory (PCI)," Int. J. Behav. Med., vol. 10. 343-63, Feb 2003. DOI: 10.1207/S15327558IJBM1004_5.

[13] D. Maki, E. Rajab, P. J. Watson, dan D. J. Critchley, "The Coping Strategies Questionnaire in an Arabic low back pain population," Summer 2018. https://www.ingentaconnect.com/content/ppa/pr/2018/00002018 /00000045/art00007\# (accessed Okt 10, 2019).

[14] N. Isgandarova, "Effective Islamic Spiritual Care: Foundations and Practices of Imams and Other Muslim Spiritual Caregivers," 2011

[15] P. J. Siddall, L. McIndoe, P. Austin, dan P. J. Wrigley, "The impact of pain on spiritual well-being in people with a spinal cord injury," Spinal Cord, vol. 55, no. 1. 105-111, Jan 2017, DOI: $10.1038 / \mathrm{sc} .2016 .75$.

[16] A. Fuady, T. Pakasi, dan M. Mansyur, "The social determinants of knowledge and perception on pulmonary tuberculosis among females in Jakarta, Indonesia," Med. J. Indones., vol. 23, hlm. 99-105, Mei 2014, DOI: 10.13181/mji.v23i2.651.

[17] B. A. Stevens, "Do We Become More Spiritual with Age?," $J$. Aging Geriatr. Med., vol. 2017, Jun 2017, Accessed: Jul 09, 2020. available: https://www.scitechnol.com/abstract/do-webecome-more-spiritual-with-age-6064.html.

[18] H. G. Koenig, MD, "Religion, Spirituality and health : research and clinical applications," dipresentasikan pada North American Association of Christians in Social Work (NACSW), USA, 2008.

[19] L. C. Callister dan K. Khalaaf, "Spirituality in childbearing women," J. Perinat. Educ., vol. 19, no. 2, hlm. 16-24, Apr 2010, DOI: $10.1624 / 105812410 X 495514$.

[20] A. Sollgruber, H. Bornemann-Cimenti, I.-S. Szilagyi, dan A. Sandner-Kiesling, "Spirituality in pain medicine: A randomized experiment of pain perception, heart rate and religious spiritual well-being by using a single session meditation methodology," PLOS ONE, vol. 13, no. 9. e0203336, Sep 2018, DOI: 10.1371/journal.pone.0203336. 